\title{
Impact of geomagnetic excursions on atmospheric chemistry and dynamics
}

\author{
I. Suter ${ }^{1}$, R. Zech ${ }^{2}$, J. G. Anet ${ }^{1}$, and T. Peter ${ }^{1}$ \\ ${ }^{1}$ Institute for Atmospheric and Climate Science ETH, Zürich, Switzerland \\ ${ }^{2}$ Geological Institute ETH, Zürich, Switzerland \\ Correspondence to: I. Suter (suter.ivo@ bluewin.ch)
}

Received: 21 October 2013 - Published in Clim. Past Discuss.: 17 December 2013

Revised: 29 April 2014 - Accepted: 6 May 2014 - Published: 19 June 2014

\begin{abstract}
Geomagnetic excursions, i.e. short periods in time with much weaker geomagnetic fields and substantial changes in the position of the geomagnetic pole, occurred repeatedly in the Earth's history, e.g. the Laschamp event about $41 \mathrm{kyr}$ ago. Although the next such excursion is certain to come, little is known about the timing and possible consequences for the state of the atmosphere and the ecosystems. Here we use the global chemistry climate model SOCOLMPIOM to simulate the effects of geomagnetic excursions on atmospheric ionization, chemistry and dynamics. Our simulations show significantly increased concentrations of nitrogen oxides $\left(\mathrm{NO}_{\mathrm{x}}\right)$ in the entire stratosphere, especially over Antarctica $(+15 \%)$, due to enhanced ionization by galactic cosmic rays. Hydrogen oxides $\left(\mathrm{HO}_{\mathrm{x}}\right)$ are also produced in greater amounts (up to $+40 \%$ ) in the tropical and subtropical lower stratosphere, while their destruction by reactions with enhanced $\mathrm{NO}_{\mathrm{x}}$ prevails over the poles and in high altitudes (by $-5 \%$ ). Stratospheric ozone concentrations decrease globally above $20 \mathrm{~km}$ by $1-2 \%$ and at the northern hemispheric tropopause by up to $5 \%$ owing to the accelerated $\mathrm{NO}_{\mathrm{x}}$-induced destruction. A $5 \%$ increase is found in the southern lower stratosphere and troposphere. In response to these changes in ozone and the concomitant changes in atmospheric heating rates, the Arctic vortex intensifies in boreal winter, while the Antarctic vortex weakens in austral winter and spring. Surface wind anomalies show significant intensification of the southern westerlies at their poleward edge during austral winter and a pronounced northward shift in spring. Major impacts on the global climate seem unlikely.
\end{abstract}

\section{Introduction}

Galactic cosmic rays (GCRs) are highly energetic particles (up to $10^{20} \mathrm{eV}$ ) from outside the heliosphere, mainly composed of protons and $\alpha$-particles, which continuously impinge on the atmosphere (Bazilevskaya et al., 2008). The Earth is shielded against the incoming particles, first by the solar magnetic field and the solar wind, which deflect GCRs away from the Earth leading to a decrease in GCR penetration into the inner heliosphere, particularly during phases of increased solar activity (Potgieter, 2013), and second, at distances of several Earth radii, by the geomagnetic field. However, neither the geomagnetic field nor the solar activity are constant over time. During the so-called Laschamp event, a geomagnetic polarity excursion of several hundred years $\sim 41$ thousand years ago (kyr), for example, the geomagnetic field experienced low inclinations or even a shortterm reversal. The field strength decreased to only $\sim 10 \%$ at its minimum. After the excursion the field rapidly recovered strength and returned to normal polarity (Nowaczyk et al., 2012). Possible effects for the atmosphere and the ecosystems have not attracted much scientific attention so far, although it is foreseeable that geomagnetic excursions will also occur in the future. The initial motivation for this study stems from the finding that glaciers in the relatively arid southern central Andes at $\sim 30-40^{\circ} \mathrm{S}$ reached their maximum extents at $\sim 40 \mathrm{kyr}$, long before the last global glacial maximum at $\sim 20 \mathrm{kyr}$ (Lowell et al., 1995; Denton et al., 1999; Espizua, 2004; Zech et al., 2007, 2008, 2011). As glaciers are not only sensitive to temperature changes, but also to precipitation (and particularly so under arid conditions), this has been interpreted as indicating a northward shift of the 
southern hemispheric westerly winds and increased precipitation at $\sim 40 \mathrm{kyr}$. A possible link to the Laschamp event has been suggested (Zech et al., 2011), which has its reasoning in the fact that GCRs have a significant influence on the upper tropospheric and stratospheric chemistry through ionization and the production of $\mathrm{NO}_{\mathrm{x}}$ and $\mathrm{HO}_{\mathrm{x}}$, which can lead to catalytic destruction of stratospheric ozone and production of tropospheric ozone (Calisto et al., 2011). A massive ozone hole during the Laschamp event has in fact recently been suggested as potential factor favouring the extinction of the Neanderthal (Valet and Valladas, 2010). Moreover, the ozone changes affect atmospheric heating rates, which in turn can result in altered temperature gradients and changing wind patterns. Thompson and Solomon (2002) suggested that stratospheric ozone depletion can cause the southern hemispheric (SH) jet to shift. The exact processes and mechanisms, however, are poorly understood. The observed southward shift of the SH westerlies over the last few decades, for example, was driven at least partly by stratospheric ozone depletion (Cai and Cowan, 2007; Son et al., 2008). Shifting $\mathrm{SH}$ westerlies due to GCRs or other forcings may have had and potentially will have a global effect on climate, because they drive Southern Ocean upwelling and deep ocean ventilation, i.e. the release of carbon dioxide from the deep ocean (Toggweiler et al., 2006). Links between changes in the geomagnetic field and global climate in the geologic past have indeed been made (Christl et al., 2004). Our model setup is not capable of diagnosing detailed, regional precipitation patterns, mainly due to the coarse resolution. Nevertheless, can we investigate large-scale features in the chemistry and associated climate, and suggest possible sensitivities in more detailed features.

Up to now, to the best of our knowledge, no chemistryclimate modelling study of the Laschamp event has been done. This study investigates the possible influence of geomagnetic excursions and solar modulation on the GCRinduced ionization in the atmosphere, atmospheric chemistry and dynamics using the atmosphere-ocean-chemistry climate model SOCOL-MPIOM. We carried out seven 51year-long simulations, which differed in strength of the geomagnetic dipole moment $(M)$, the latitude of the geomagnetic pole and the solar modulation potential $(\phi)$.

\section{Model description}

The model SOCOL-MPIOM consists of the middle atmosphere version of the global circulation model ECHAM5 (Roeckner et al., 2003, 2006; Manzini et al., 2006), a modified version of the chemistry model MEZON (Rozanov et al., 1999, 2001; Egorova et al., 2003; Hoyle, 2005) and has been coupled with OASIS3 (Valcke, 2013) to the ocean model MPI-OM (Marsland et al., 2003). Versions 1 and 2 of SOCOL, based on MA-ECHAM4, have been validated by Egorova et al. (2005) and Schraner et al. (2008). SOCOLv3 was recently developed by Stenke et al. (2013), who coupled the chemistry and dynamics routines to MA-ECHAM 5.4.00, improved the advection scheme for chemical species and enabled it to be fully parallelized. SOCOLv3 improves some previous deficiencies in chemical transport. The chemical processes triggered by solar energetic particles (SEP) and GCRs have recently been implemented in SOCOLv2 by Calisto et al. (2011) and in SOCOLv3 by Anet et al. (2013).

The CRAC:CRII (Cosmic Ray Atmospheric Cascade: Application for Cosmic Ray Induced Ionization, Usoskin and Kovaltsov, 2006; Usoskin et al., 2010) model was used to describe the effect of GCRs in the entire horizontal and vertical model domain. CRAC:CRII is able to calculate the effect of $\phi$ and the geomagnetic field on GCRs. The solar modulation potential $\phi$ is used to describe the deceleration of precipitating particles due to their interaction with the solar wind (Gleeson and Axford, 1968; Caballero-Lopez and Moraal, 2004; Usoskin et al., 2005). It influences the amount and energy spectrum of particles which pass the heliosphere and reach Earth's magnetopause. The geomagnetic field $M$ affects the further penetration into the Earth's atmosphere depending on the incoming energy spectrum and latitude. CRAC:CRII performed a Monte Carlo simulation of the nucleonic-muon-electromagnetic cascade following the penetration of an energetic particle into the atmosphere. The ionization is a function of altitude, geomagnetic latitude, field strength and the solar activity. The ionization rates calculated by CRAC:CRII are tabulated and converted to a $\mathrm{NO}_{\mathrm{x}}$ and $\mathrm{HO}_{\mathrm{x}}$ production rate, by means of simple parameterization, since SOCOL does not treat ion chemistry explicitly. We use a constant conversion factor for $\mathrm{NO}_{\mathrm{x}}$ of 1.25 nitrogen atoms per ion pair (Porter et al., 1976) - of which $45 \%$ yield $\mathrm{N}\left({ }^{4} \mathrm{~S}\right)$ and $55 \%$ yield $\mathrm{N}\left({ }^{2} \mathrm{D}\right)$. The latter instantaneously converts into $\mathrm{NO}$ via $\mathrm{N}\left({ }^{2} \mathrm{D}\right)+\mathrm{O}_{2} \rightarrow \mathrm{NO}+\mathrm{O}$. For $\mathrm{HO}_{\mathrm{x}}$ we implemented the parameterization of Solomon et al. (1981). They examined the thermodynamics of ion and neutral chemistry during charged-particle precipitation events to describe odd hydrogen production depending on altitude and ionization rate and found values between 1.9 and 2 odd hydrogen molecules produced per ion pair below $60 \mathrm{~km}$ altitude.

We use SOCOL-MPIOM in T31 horizontal resolution, i.e. with an approximate grid spacing of $3.75^{\circ} \times 3.75^{\circ}$ and 39 vertical hybrid sigma-p levels, terrain-following sigma levels at the bottom and isobaric coordinates aloft. The vertical coordinates span the atmosphere from surface to $1 \mathrm{~Pa}$ $(\sim 80 \mathrm{~km})$. It contains 41 chemical species, which interact via 140 gas phase, 46 photolytic and 16 heterogeneous reactions.

MPI-OM is based on the primitive equations and uses hydrostatic and Boussinesq approximations. Horizontal discretization is on an orthogonal curvilinear C-grid, while in the vertical isopycnic coordinates are used. MPI-OM includes a dynamic and thermodynamic sea ice model. 


\section{Model setup}

A 400-year spin-up run of the model was performed under glacial conditions at $\sim 41 \mathrm{kyr}$. The Earth's orbital parameters were set accordingly. The initial land surface data set (e.g. ice cover) and ocean temperatures are from an earlier glacial simulation with ECHAM5 (M. Thürkow, personal communication, 2012). The atmosphere was in a pristine state, we set concentrations of greenhouse gases and ozone depleting substances to pre-industrial values $\left(\left[\mathrm{CH}_{4}\right],\left[\mathrm{N}_{2} \mathrm{O}\right]\right.$, $\left[\mathrm{CO}_{2}\right]$ from Schilt et al., 2010, $\left[\mathrm{CH}_{3} \mathrm{Cl}\right]$ from Saltzman et al., 2009, $\left[\mathrm{CH}_{3} \mathrm{Br}\right]$ from Liebowitz et al., 2009). After spin-up the model has a globally averaged mean annual $2 \mathrm{~m}$ temperature of $\sim 284.25 \mathrm{~K}$. This is about $4 \mathrm{~K}$ colder than present-day conditions and in reasonable agreement with palaeo-records for the last glacial maximum and other model results (Mix et al., 2001; Braconnot et al., 2007; Jansen et al., 2007).

We then branched off seven 51-year-long simulations (Table 1). While trace gas concentrations, intensity of the geomagnetic field, position of the geomagnetic pole and solar properties were further held constant for the reference run, three simulations were carried out with only $10 \%$ of the dipole moment (M10), i.e. with significantly reduced field strength. In two of these three simulations the position of the magnetic pole was varied additionally, once to $45^{\circ}$ and once to $0^{\circ}$ (M10P45 and M10P0), in order to perform runs under conditions close to the Laschamp event. The geomagnetic dipole was assumed as centred and its longitude set to $291.5^{\circ} \mathrm{E}$ in all the simulations. Three more simulations were carried out as sensitivity tests. M0 has a dipole moment set to zero. PHIO has a normal magnetic field, but solar modulation potential set to zero. MOPHIO has both dipole moment and the solar modulation potential $\phi$ set to zero. The reference $\phi$ value was arbitrarily chosen and lies at the lower end of natural variability, while a zero $\phi$ is very unlikely and should be considered as a sensitivity test only. We simplified the geomagnetic field as a dipole in all simulations without higher-order geomagnetic field components.

\section{Results and discussion}

In the following results and discussion, we start by analysing mean annual changes in atmospheric chemistry and dynamics, before also presenting examples of seasonal changes. Note that we partly talk about causalities, although we are aware that this simplifies the fact that feedback mechanisms are at work and we basically observe consistent changes of several parameters.

\subsection{Changes in atmospheric chemistry}

\subsection{1 $\mathrm{NO}_{\mathrm{x}}$ concentrations}

The zonally averaged mean annual $\mathrm{NO}_{\mathrm{x}}$ concentrations $\left(\left[\mathrm{NO}_{\mathrm{x}}\right]=[\mathrm{NO}]+\left[\mathrm{NO}_{2}\right]\right)$ show significant increases in the
Table 1. Overview over the simulations that were carried out. The reference run has present-day solar and geomagnetic fields. Dipole moment in $\%$ of $8.25 \times 10^{22} \mathrm{~A} \mathrm{~m}^{2} . \phi$ in $\mathrm{MV}$.

\begin{tabular}{lrrr}
\hline Run & Dipole moment & Latitude of pole & $\phi$ \\
\hline M10 & $10 \%$ & $78.5^{\circ}$ & 400 \\
M10P45 & $10 \%$ & $45^{\circ}$ & 400 \\
M10P0 & $10 \%$ & $0^{\circ}$ & 400 \\
\hline M0 & $0 \%$ & $78.5^{\circ}$ & 400 \\
M0PHI0 & $0 \%$ & $78.5^{\circ}$ & 0 \\
PHI0 & $100 \%$ & $78.5^{\circ}$ & 0 \\
\hline Reference & $100 \%$ & $78.5^{\circ}$ & 400 \\
\hline
\end{tabular}

stratosphere in all six simulations (Fig. 1). Simulations M10, $\mathrm{M} 10 \mathrm{P} 45, \mathrm{M} 10 \mathrm{P} 0$ and M0 look very similar, since they all have a weak geomagnetic field, which allows more cosmic radiation to reach the atmosphere and results in enhanced ionization and production of $\mathrm{N}, \mathrm{NO}$ and $\mathrm{OH}$. A change of the position of the geomagnetic pole has a smaller additional effect. The greatest effects of enhanced ionization occur between 16 and $25 \mathrm{~km}$, the Pfotzer maximum (Bazilevskaya and Svirzhevskaya, 1998). $\mathrm{NO}_{\mathrm{x}}$ shows a significant increase in the entire stratosphere above $200 \mathrm{hPa}(\sim 12 \mathrm{~km})$. Antarctic stratospheric concentrations rise by $15 \%$. The Arctic shows a smaller increase of $5 \%$. This asymmetry between the Northern Hemisphere and Southern Hemisphere is due to the fact that reference $\mathrm{NO}_{\mathrm{x}}$ concentrations around $100 \mathrm{hPa}$ are lower in the Southern Hemisphere. No strong increase can be found in the troposphere - some regions even show a small decrease, although without statistical significance at the $5 \%$ confidence level. Note that although the strength of the magnetic field strongly controls the GCR intensity at low latitudes (due to the perpendicular orientation of the field), the long lifetime of $\mathrm{NO}_{\mathrm{x}}$ allows for an efficient latitudinal distribution. In PHIO, $\mathrm{NO}_{\mathrm{x}}$ concentrations increase particularly at high latitudes, because the magnetic field lines on the poles are almost parallel to the incoming GCRs. These are therefore mainly modulated by $\phi$, while the magnetic field has a minor influence. Vice versa, the effect of $\phi$ is small at low latitudes since there the magnetic field provides efficient shielding (as long as the field intensities are not reduced). The MOPHI0 simulation represents the most extreme case of enhanced ionization in our study. The absence of the geomagnetic field and of the solar modulation potential $\phi$, i.e. no shielding from GCRs, causes a $\mathrm{NO}_{\mathrm{x}}$ increase of more than $20 \%$ in the lower stratosphere.

\subsection{2 $\mathrm{HO}_{\mathrm{x}}$ concentrations}

Concentrations of hydrogen oxides $\left(\left[\mathrm{HO}_{\mathrm{x}}\right]=\left[\mathrm{HO}_{2}\right]+[\mathrm{OH}]\right.$ $+[\mathrm{H}])$, which are also produced by galactic cosmic rays, reveal a very similar pattern for the experiments M10, M10P45, M10P0 and M0, indicating again that the pole 

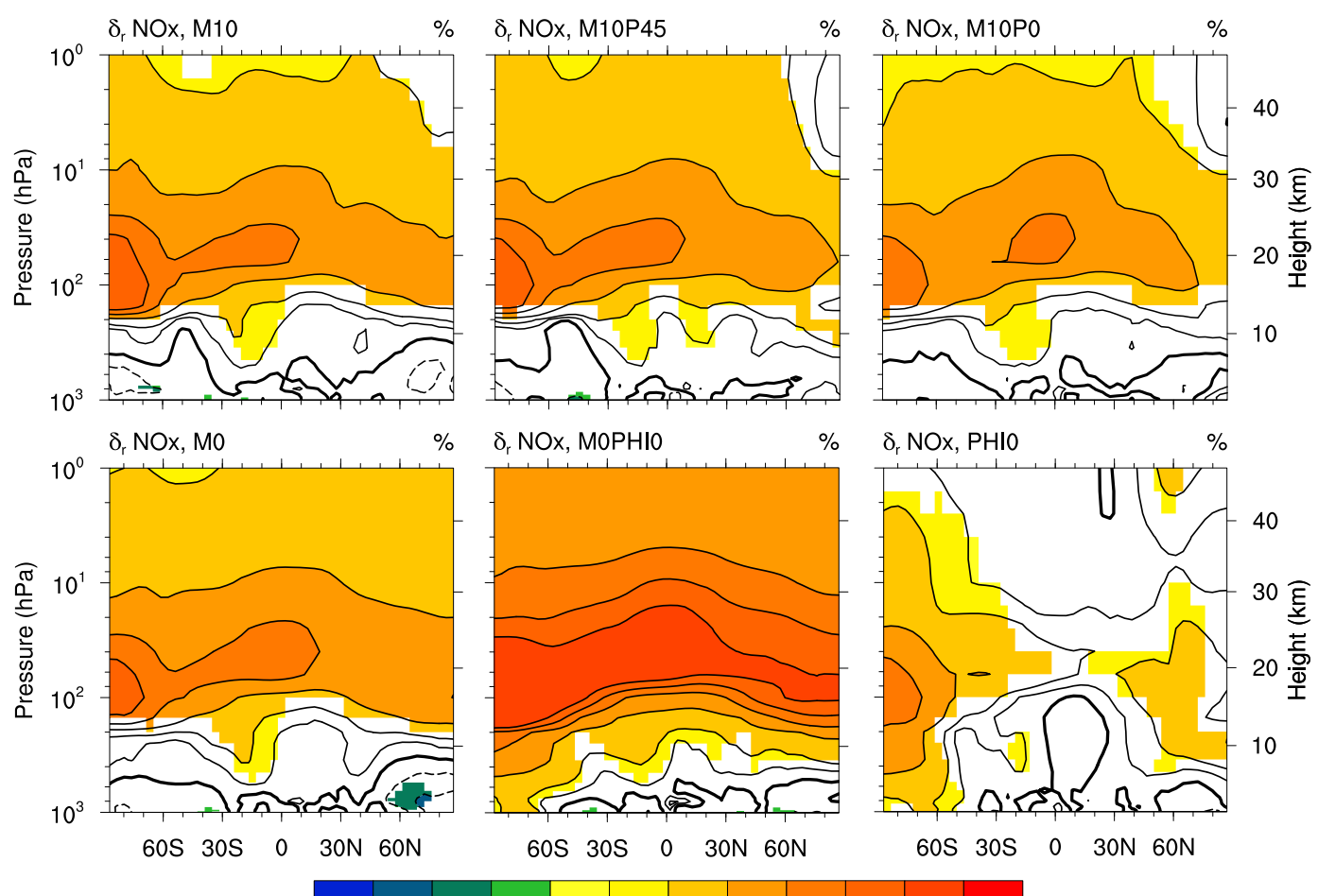

$-5 \quad-2$

Figure 1. Simulated effects on zonally averaged mean annual $\mathrm{NO}_{\mathrm{x}}$ concentrations. The relative difference is defined as $\left([X]_{\exp }-[X]_{\text {ref }}\right) /[X]_{\text {ref }}$. Coloured areas are significant at a $5 \%$ level. Solid contours indicate positive, dashed contours negative changes.

position is less important for changes in ionization than field strength (Fig. 2). Distinct increases in $\mathrm{HO}_{\mathrm{x}}(+50 \%)$ are found in the tropical and subtropical upper troposphere and lower stratosphere (UTLS) up to $25 \mathrm{~km}$. The strong increase emphasizes the importance of GCRs as a $\mathrm{HO}_{\mathrm{x}}$ source in those altitudes. $\mathrm{HO}_{\mathrm{x}}$ lifetimes are small compared to $\mathrm{NO}_{\mathrm{x}}$ resulting in localized increases only in the source areas at low latitudes. Above $25 \mathrm{~km}$ and in polar areas above $\sim 10 \mathrm{~km} \mathrm{HO}_{\mathrm{x}}$ concentrations are reduced due to reaction with the additional $\mathrm{NO}_{\mathrm{x}}\left(\mathrm{OH}+\mathrm{NO}_{2} \rightarrow \mathrm{HNO}_{3}\right)$. A reduced solar modulation potential $\phi$ (simulation PHI0) leads to an increase of ionization above the poles and additional production of $\mathrm{HO}_{\mathrm{x}}$. Here the reaction with the additional $\mathrm{NO}_{\mathrm{x}}$ is not efficient enough to result in reduced $\mathrm{HO}_{\mathrm{x}}$ concentrations in high latitudes. Instead, $\mathrm{HO}_{\mathrm{x}}$ concentrations now decrease at low latitudes. Simulation MOPHIO is a superposition of both effects and results in a net increase below $\sim 20 \mathrm{~km}$ and a net decrease above $20 \mathrm{~km}$.

\subsubsection{Ozone concentrations}

Figure 3 shows the response of ozone to the changes in $\mathrm{NO}_{\mathrm{x}}$ and $\mathrm{HO}_{\mathrm{x}}$. In all four simulations with a weaker geomagnetic field (M10, M10P45, M10P0, M0) ozone concentrations show a significant decrease by more than $1 \%$ above
$20 \mathrm{~km}$. The additional $\mathrm{NO}_{\mathrm{x}}$ catalytically destroys ozone:

$\mathrm{NO}+\mathrm{O}_{3} \rightarrow \mathrm{NO}_{2}+\mathrm{O}_{2}$

$\mathrm{NO}_{2}+\mathrm{O} \rightarrow \mathrm{NO}+\mathrm{O}_{2}$

$\mathrm{O}_{3}+\mathrm{h} v \rightarrow \mathrm{O}_{2}+\mathrm{O}$

Net : $2 \mathrm{O}_{3} \rightarrow 3 \mathrm{O}_{2}$.

$\mathrm{HO}_{\mathrm{x}}$, also able to destroy ozone catalytically, is enhanced in an area where ozone concentrations are predominantly determined by pure oxygen chemistry. Therefore the effect of the strongly increased $\mathrm{HO}_{\mathrm{x}}$ concentrations in the tropical and subtropical UTLS on ozone remains marginal.

Ozone concentrations decrease significantly $(-5 \%)$ at the arctic tropopause. In addition to chemistry, dynamics and feedback processes play an important role here. The additional $\mathrm{NO}_{\mathrm{x}}$ in the Arctic leads to a decrease in ozone in November. Consequently the polar stratosphere cools due to reduced absorption of outgoing infrared radiation. This enhances the pole to equator temperature gradient, leading to an intensification of the circumpolar vortex during its formation (more detailed discussion in dynamics section below, in particular Figs. 4 and 5). A stronger vortex in turn better insulates the arctic air masses, resulting in more radiative cooling and reduced ozone transport from the tropics, causing a positive feedback. The tropospheric ozone decrease is partly attributed to the reduced ozone transport from the 

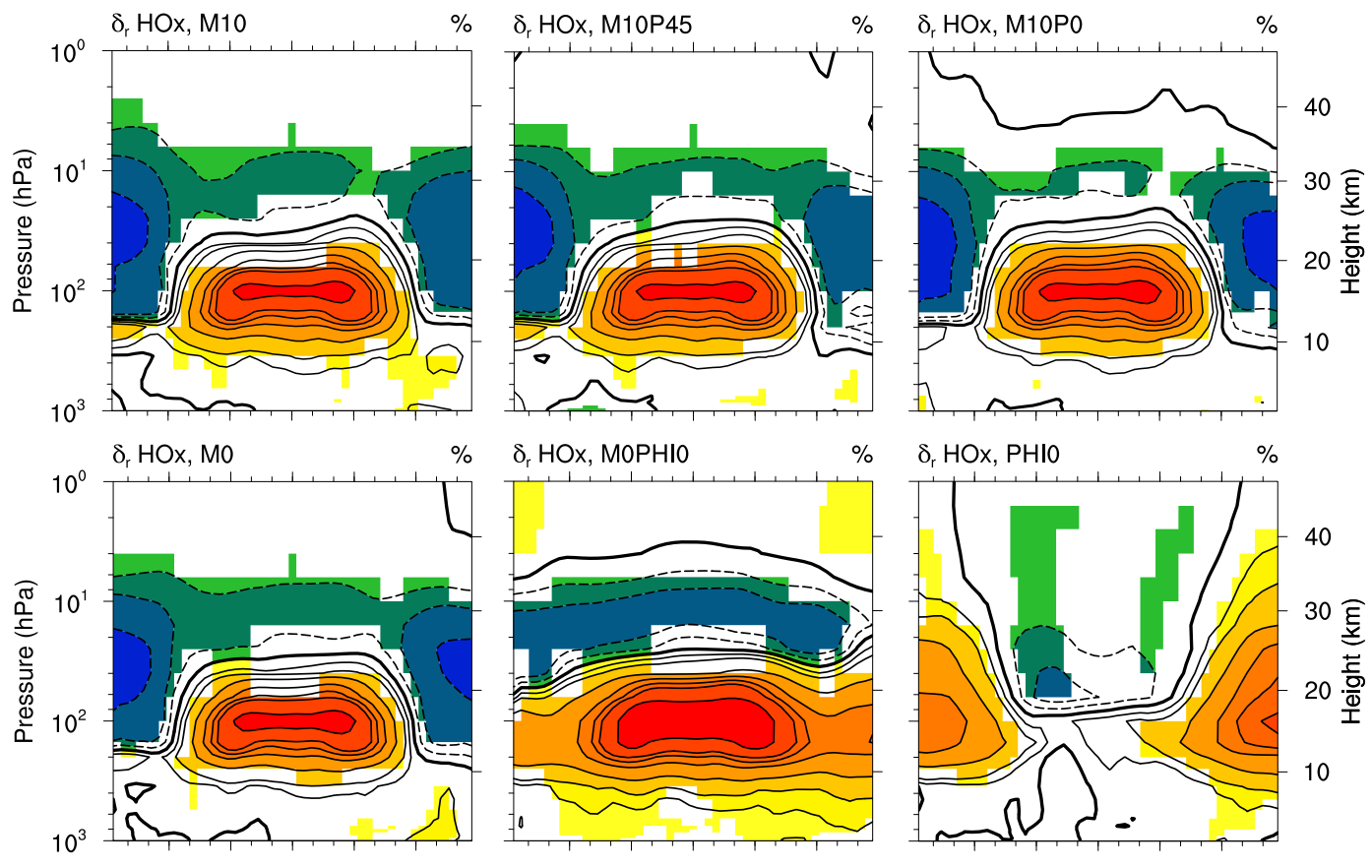

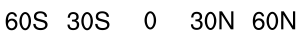

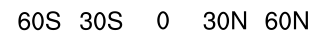

60S $30 \mathrm{~S} \quad 0 \quad 30 \mathrm{~N} 60 \mathrm{~N}$

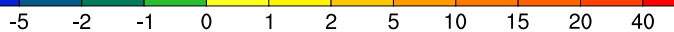

Figure 2. Simulated effects on zonally averaged mean annual $\mathrm{HO}_{\mathrm{x}}$ concentrations. Coloured areas are significant at a $5 \%$ level. Solid contours indicate positive, dashed contours negative changes.

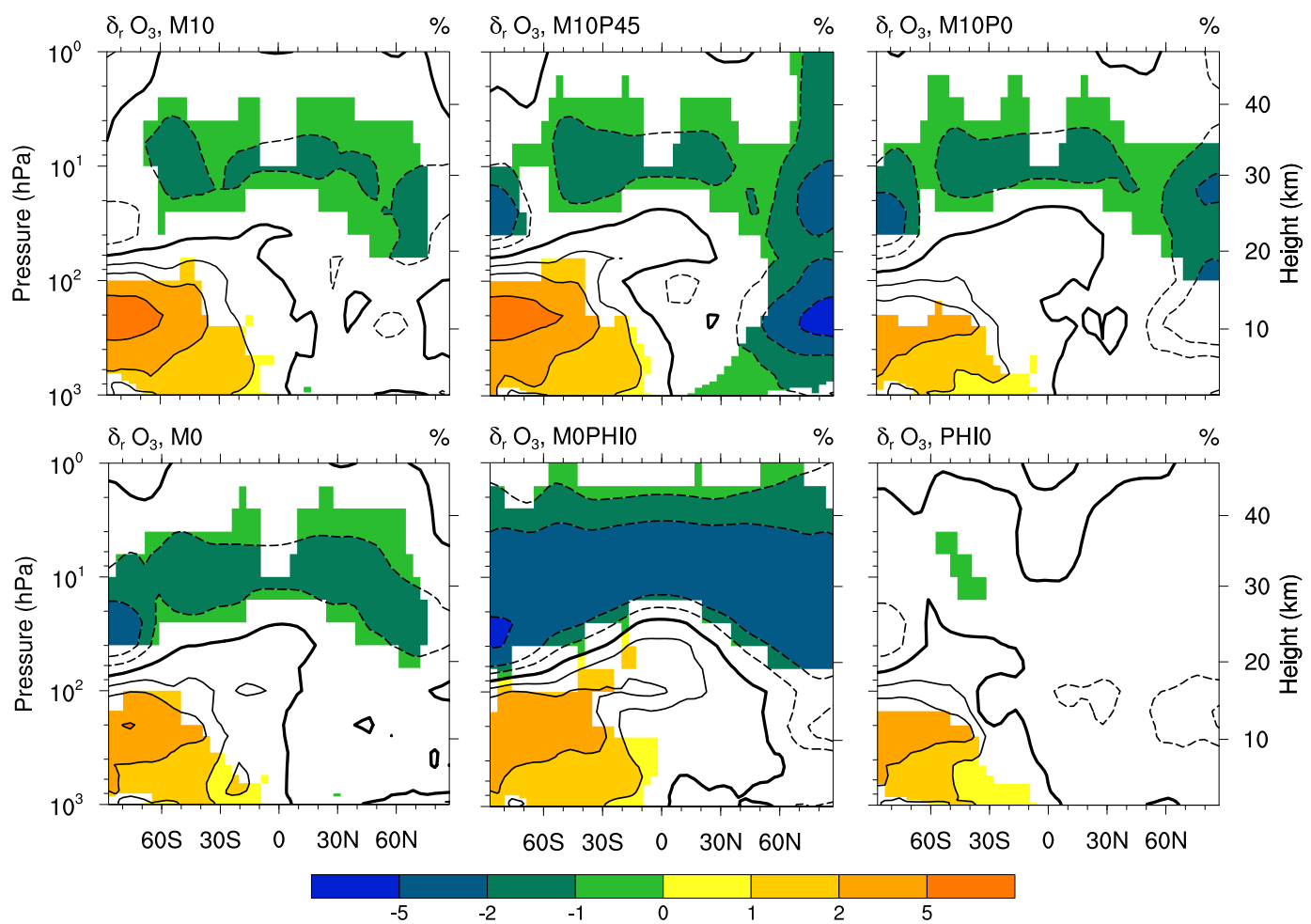

Figure 3. Simulated effects on zonally averaged mean annual ozone concentrations. Coloured areas are significant at a $5 \%$ level. Solid contours indicate positive, dashed contours negative changes. 

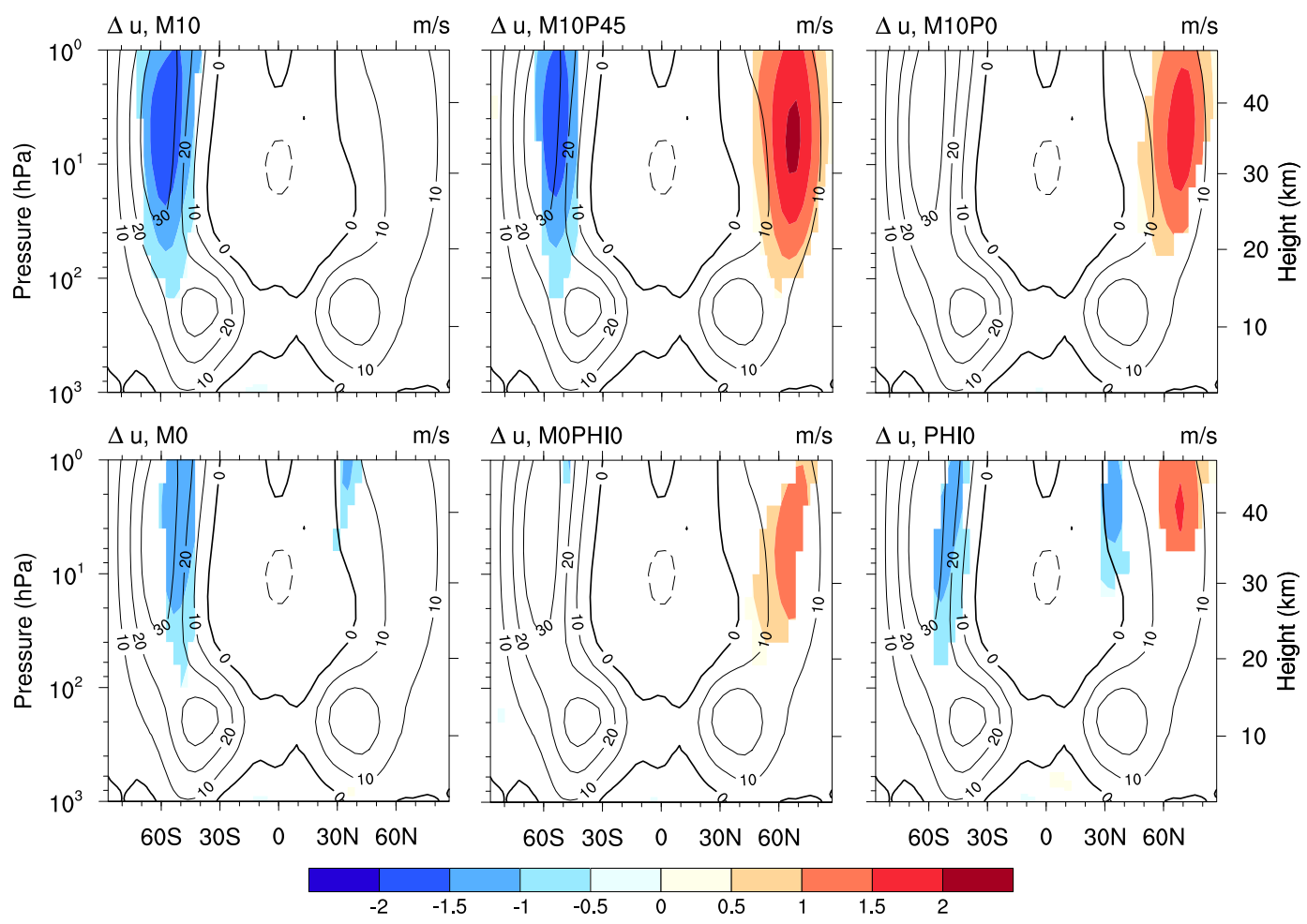

Figure 4. Simulated effects on zonally averaged mean annual zonal wind $(u)$. Coloured areas are significant at a $10 \%$ level. Contours show the actual wind velocity of the reference run in $10 \mathrm{~m} \mathrm{~s}^{-1}$ intervals.

lower stratosphere. After vortex breakup in spring, concentrations recover. Note that the feedback described above for M10P45 developed in response to only small differences in $\mathrm{HO}_{\mathrm{x}}$ and $\mathrm{NO}_{\mathrm{x}}$ compared to M10 and M0, which illustrates high sensitivity of atmospheric ozone chemistry and dynamics to minor differences in $\mathrm{NO}_{\mathrm{x}}$ and $\mathrm{HO}_{\mathrm{x}}$.

In contrast to the Northern Hemisphere, it is interesting to see significant increases in ozone in the southern polar UTLS $(\sim 5 \%)$. This is a robust feature in most simulations, in particular in M10P45. On the one hand, less ozone is destroyed due to less $\mathrm{HO}_{\mathrm{x}}$ above $200 \mathrm{hPa}$. On the other hand, we argue for enhanced photochemical production of ozone. In contrast to the Northern Hemisphere, Antarctic $\mathrm{NO}_{\mathrm{x}}$ concentrations are naturally lower, because (i) colder temperatures cause higher denitrification in winter, and (ii) lightnings, a major natural $\mathrm{NO}_{\mathrm{x}}$ source, are less common over the vast oceans than over land, leading to a smaller influx from the troposphere. The ozone chemistry over Antarctica is thus $\mathrm{NO}_{\mathrm{x}}$ limited and additional $\mathrm{NO}_{\mathrm{x}}$ can accelerate photochemical ozone formation. Support for this reasoning comes from comparison with the simulations MOPHIO and PHI0, which show ozone increases in the southern hemispheric UTLS despite increases in $\mathrm{HO}_{\mathrm{x}}$. Furthermore, all three simulations first show higher ozone concentrations at the edge of the Antarctic winter vortex and then successively towards the pole in austral spring (Fig. 5).

\subsection{Changes in atmospheric dynamics}

\subsubsection{Zonal winds}

Ozone and many other chemical species in the atmosphere absorb IR and UV radiation and thus influence temperature. Higher ozone concentrations in our simulations over Antarctica (Fig. 3), for example, lead to warming and a reduced pole to equator temperature gradient. This can cause a weakening of westerly winds with height due to the thermal wind relationship

$\boldsymbol{v}_{\mathrm{T}}=\frac{R}{f} \cdot \ln \left(\frac{p_{0}}{p_{1}}\right) \boldsymbol{k} \times \nabla_{\mathrm{p}} T$,

where $\boldsymbol{v}_{\mathrm{T}}$ is the thermal wind vector, $R$ is the specific gas constant for dry air, $f$ is the Coriolis parameter, $p_{0}$ and $p_{1}$ are two pressure levels, $\boldsymbol{k}$ is the vertical unit vector and $\nabla_{\mathrm{p}} T$ is the temperature gradient on a constant pressure surface. We see significant anomalies in the mean annual zonal wind fields above $15 \mathrm{~km}$ altitude and at high latitudes for all our simulations. The general observations are easterly anomalies in the south and westerly anomalies in the north (Fig. 4). However, stratospheric zonal winds reverse semiannually and analysing wind anomalies in particular seasons might provide more detailed insights.

Figure 5 illustrates the changes in ozone concentration and the zonal wind anomalies in January, August and November 


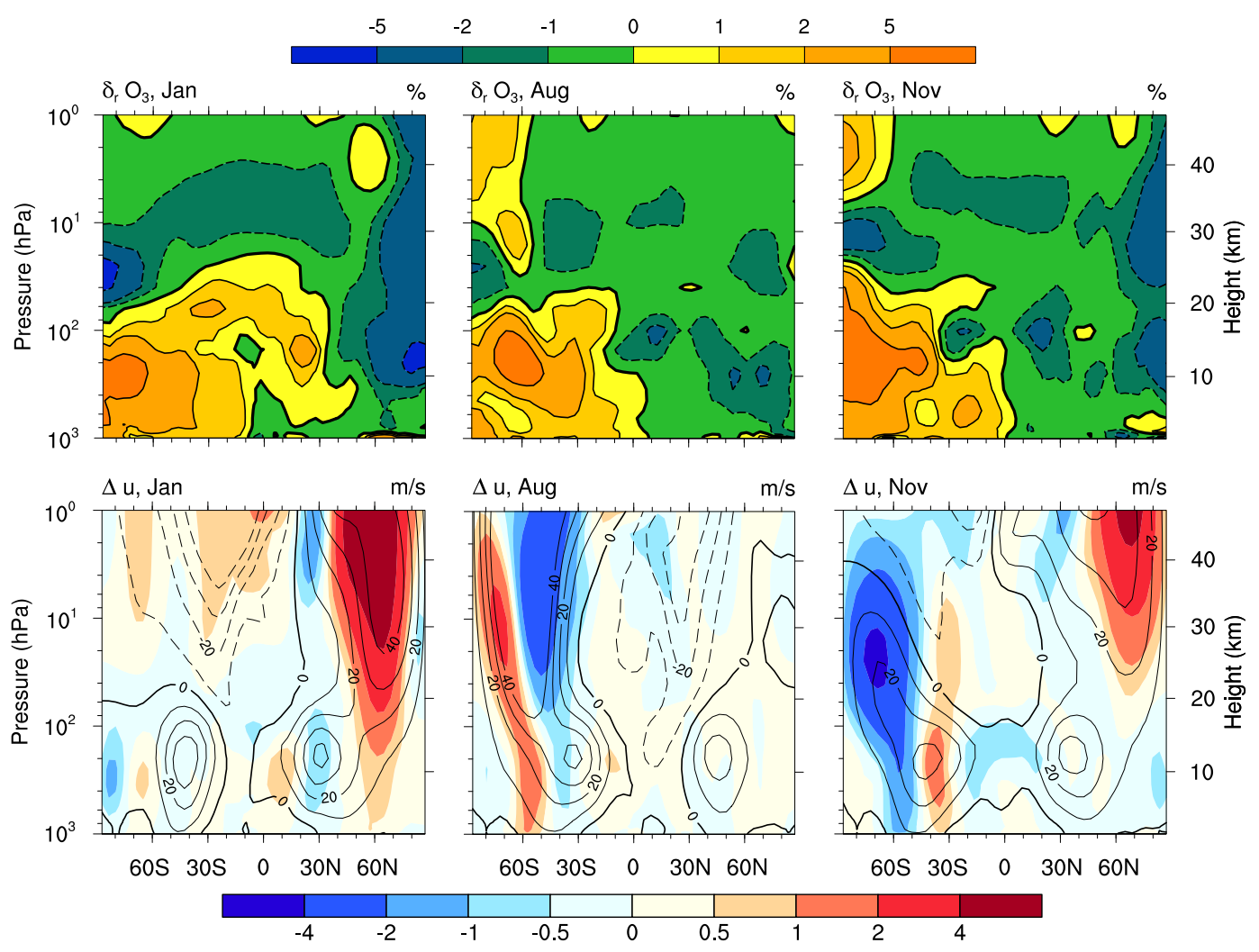

Figure 5. Simulated monthly ozone anomalies (upper panel, as in Fig. 3) and zonal winds (lower panel, as in Fig. 4). Results are shown for simulation M10P45.

for M10P45. This simulation was exemplarily chosen since it shows the strongest anomalies and conditions which closely resemble the Laschamp event. The Arctic vortex is significantly intensified in January due to low ozone concentrations and lower temperatures, while the lower-latitude westerlies become weaker. There is basically a slight shift of the tropospheric westerlies towards the pole. Note that similar observations and interpretations are made today in the Southern Hemisphere and are related to the man-made ozone hole and an altered temperature gradient in the UTLS. For comparison, temperatures in the lower stratosphere drop by $2 \mathrm{~K}$ in our simulation, while in today's ozone hole reductions of $\sim 10 \mathrm{~K}$ can be observed. The detailed mechanisms by which stratospheric ozone depletion can cause a shift of the tropospheric westerlies are still debated (Thompson and Solomon, 2002; Son et al., 2010; Polvani et al., 2011) and we will only briefly mention them here. We find mean annual sea level pressure anomalies of $+0.5 \mathrm{hPa}$ over Antarctica and $-1 \mathrm{hPa}$ over the Arctic compared to the reference simulation. This is a bias towards a high-index $\mathrm{NH}$ annular mode and a low-index SH annular mode. Annular modes are well studied patterns explaining large parts of climate variability in the Northern Hemisphere and Southern Hemisphere middle and high latitudes. Simultaneously, the tropopause is lowered over Antarctica $(+2 \mathrm{hPa})$ and lifted over the Arc- tic $(-3 \mathrm{hPa})$. A higher tropopause shifts the jet stream to higher latitudes and leads to an expansion of the Hadley cell, likely due to the interaction with baroclinic eddies (Son et al., 2010). We do, however, not fully understand why we do not see more pronounced Antarctic wind anomalies in January, even though tropospheric ozone strongly increases and stratospheric ozone decreases. In August a large positive ozone (and thus temperature) signal can be found between 40 and $70^{\circ} \mathrm{S}$ at $10-15 \mathrm{~km}$ altitude, slowly growing towards the pole in the following months. As a temperature maximum is found at $\sim 50^{\circ}$ at these altitudes in the winter hemisphere, the thermal wind relation predicts weaker stratospheric winds to the north and stronger winds to the south of the temperature anomaly in the Southern Hemisphere. With the positive ozone signal growing towards the pole during the austral winter and spring, the negative wind pattern also moves polewards. Finally, in November the negative wind anomalies have moved $30^{\circ}$ polewards and the SH westerlies intensify on the equatorward edge. This is caused by the increase of Antarctic ozone and warming of the polar air in spring. The equatorward shift of the $\mathrm{SH}$ westerlies is most pronounced in austral spring and weakens again in summer. Note that the wind anomalies clearly reach into the troposphere, which cannot be explained by simple geostrophic 
wind theory. Instead the same argumentation as for today's downward control has to be used.

\subsubsection{Seasonal surface winds and precipitation}

Surface wind anomalies (shown in Fig. 6 for M10P45) allow us to examine spatial and seasonal variations in more detail. At high northern latitudes, a few westerly anomalies are statistically significant from December to May, which likely corresponds to the stratospheric intensification of the polar vortex described above. However, most of the surface wind changes in the Northern Hemisphere are not particularly systematic and only weak. This is also the case for the southern hemispheric surface winds from March to May. In JJA, however, the SH westerlies significantly intensify on the polar edge and locally also in the core. In SON, the SH westerlies then shift significantly equatorward. This pattern persists for several months and is still faintly visible in DJF.

The simulations M10, M10P45, M10P0 and M0 all indicate slightly enhanced mean annual precipitation south of $40^{\circ} \mathrm{S}$ over Chile and Argentina, but these changes are not statistically significant on a $10 \%$ significance level. MOPHIO shows an insignificant decrease in precipitation and PHIO virtually no change at all. Unfortunately, due to the low T31 resolution version of SOCOL-MPIOM, orographic precipitation in the Andes cannot be fully captured and with regard to the initial motivation for this study, the possible effect of the Laschamp event on the glacial mass balances in the southern central Andes cannot be evaluated directly. However, given that the precipitation in the southern Andes is strongly controlled by the southern westerlies (Garreaud, 2007), one can tentatively interpret the above changes in the westerlies in terms of precipitation and snow accumulation on the glaciers. The southward shift of the SH westerlies in austral winter is probably the most relevant observation, because austral winter is the crucial season for advecting moisture to the southern central Andes between 30 and $40^{\circ} \mathrm{S}$. For austral winter, our simulations thus basically show the opposite of the hypothesized northward shift during a geomagnetic excursion. It remains unclear at this point why glaciers reached maximum extent. One could speculate that the significant northward shift simulated for austral spring compensates for less moisture advection in winter and that the overall effect could be positive glacier mass balances and glacier advances.

\subsection{Palaeoclimatic evidence for the Laschamp event}

As models per se may not include all relevant processes to perform adequate simulations, it is common practice to do model-data comparisons. We therefore attempted to review the most relevant palaeoclimate records apart from the glacial chronologies that reach back to the Laschamp event. This is challenging, because most records suffer from considerable dating uncertainties and the palaeoclimatic interpretation of virtually all proxies is not straightforward. Note that controversies about the position and strength of the $\mathrm{SH}$ westerlies during the last glacial maximum at $\sim 20 \mathrm{kyr}$ go back several decades, with many more palaeodata and model studies having focused on that time period (Heusser, 1989; Markgraf et al., 1992; Kohfeld et al., 2013; Sime et al., 2013) than on the Laschamp event. The few records from South America, which have been interpreted to record past changes in the $\mathrm{SH}$ westerlies and related precipitation, do not provide a fully consistent picture. Low $\delta^{18} \mathrm{O}$ values in the Laguna Tagua Tagua in central Chile $\left(34^{\circ} \mathrm{S}\right)$, for example, may reflect colder temperatures and/or enhanced winter precipitation from 40-20 kyr, while particularly arid conditions seem to have prevailed from 42.4-40.1 kyr (Valero-Garces et al., 2005). Pollen spectra in the Atacama Desert further north $\left(25^{\circ} \mathrm{S}\right)$ have been interpreted to document enhanced winter precipitation due to expanded southern westerlies from 40 to $33 \mathrm{kyr}$ and from 24 to $14 \mathrm{kyr}$ (Maldonado et al., 2005). Stuut and Lamy (2004) on the other hand, argued for wet periods from 52 to $41 \mathrm{kyr}$ and 40 to $38 \mathrm{kyr}$, but dry conditions from $38-28 \mathrm{kyr}$, based on grain-size analyses in a deep-sea sediment core off the Chilean cost. Finally Hahn et al. (2013) reported increased biogenic silica contents between 41 and $37 \mathrm{kyr}$ from the Laguna Potrok Aike in Argentina (52 $\mathrm{S}$ ), yet the palaeoenvironmental reasons for this increase remain unclear. This small compilation shows that at this point the available records don't help resolving the question whether the Laschamp event may have affected the climate in the southern Andes.

We also reviewed high-resolution, well-dated records from outside the southern mid-latitudes. Speleothems in Brazil, for example, document increased precipitation at $\sim 39 \mathrm{kyr}$, whereas speleothems from China synchronously document more arid conditions (Y. J. Wang et al., 2001; X. Wang et al., 2007). This anti-phasing in the speleothems, and many other published palaeoclimate records, reflect a southward shift of the intertropical convergence zone at $39 \mathrm{kyr}$, which corresponds to Heinrich event 4 (Voelker, 2002; Hemming, 2004). Heinrich events are recurring episodes of massive icerafting in the North Atlantic during glacials, yet they are only the most severe of dozens of rapid and dramatic climate changes recorded in Greenland ice cores. Three of the so-called Dansgaard-Oeschger warming events occurred between 45 and $40 \mathrm{kyr}$ (Greenland interstadials 9, 10 and 11) before the Heinrich event 4 started. There is no robust evidence for correlations between any of these events and geomagnetism (Nowaczyk et al., 2012). Vice versa, palaeodata do not show a significant global climate impact of the Laschamp event.

\section{Conclusion and outlook}

The results of our simulations indicate that geomagnetic excursions, as well as low solar modulation, have significant impacts on atmospheric chemistry and dynamics. 
$\Delta 10 \mathrm{~m}$ wind, DJF

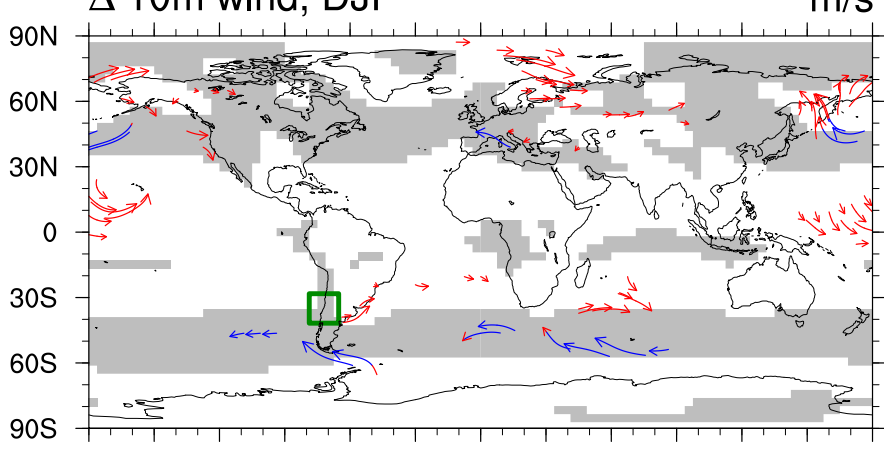

$\Delta 10 \mathrm{~m}$ wind, JJA

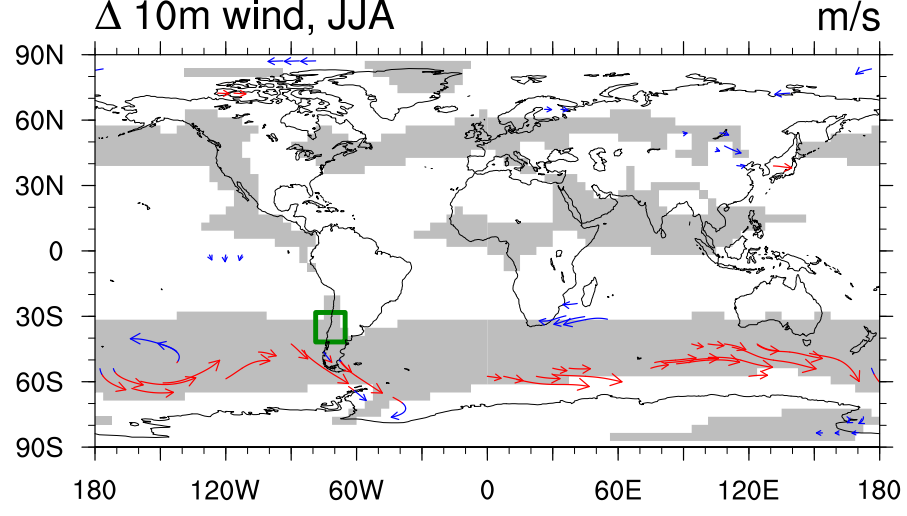

$\Delta 10 \mathrm{~m}$ wind, MAM $\mathrm{m} / \mathrm{s}$

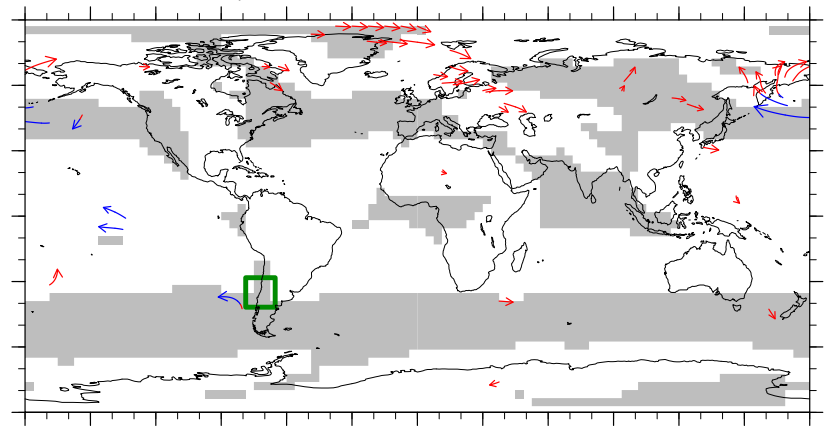

$\Delta 10 \mathrm{~m}$ wind, SON

$\mathrm{m} / \mathrm{s}$

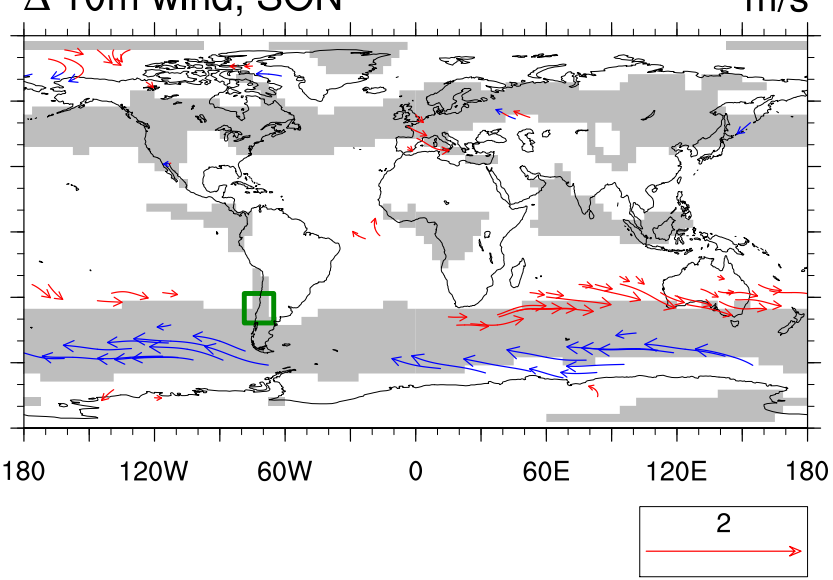

Figure 6. Simulated effects on seasonal $10 \mathrm{~m}$ surface winds. Results are shown for M10P45. Vectors show strength and direction of the change in $10 \mathrm{~m}$ wind. Vectors are coloured based on the direction of change in zonal wind in the corresponding grid box (red for a significant increase, blue for a significant decrease in zonal component on a $10 \%$ significance level). Only vectors with a significant change in wind, on a $10 \%$ level, are shown. Grey contours show areas with positive zonal wind component (westerlies) of the reference run. The green square marks the southern central Andes between 30 and $40^{\circ}$, where glacial maxima occurred at $\sim 40 \mathrm{kyr}$.

Our simulation suggests substantial increases in hydrogen and nitrogen oxide concentrations as a consequence of enhanced ionization by GCRs. Ozone concentrations increase significantly $(2-5 \%)$ at high southern latitudes and below $\sim 20 \mathrm{~km}$ in all our simulations, while concentrations decline at $\sim 30 \mathrm{~km}$ at all latitudes. Significant ozone destruction is observed at all altitudes over the Arctic in simulation M10P45, illustrating the sensitivity of the model to small initial differences in atmospheric chemistry and the importance of positive feedback mechanisms between atmospheric chemistry and dynamics.

Particularly the changing ozone concentrations are responsible for significant zonal wind anomalies, up to $5 \mathrm{~m} \mathrm{~s}^{-1}$ in the stratosphere and $2 \mathrm{~m} \mathrm{~s}^{-1}$ in the troposphere. The general response is a strengthening of the northern hemispheric vortex in boreal winter, and a weakening of the southern hemispheric vortex in austral winter and spring. Significant anomalies are also simulated for the surface winds, particularly an intensification of the SSW on their polar edge in austral winter and a pronounced northward shift during austral spring. It remains unclear at this point, whether related precipitation changes could have caused more positive glacier mass balances and glacier advances in the southern central Andes during the Laschamp event. Available palaeodata from other records in southern South America are inconsistent. Regional models might provide more insights into possible precipitation changes in the Andes. High-resolution and well-dated polar ice core and subtropical speleothem records at least are in good agreement with our model showing that geomagnetic excursions very likely do not have direct and significant impacts on the global climate.

Future studies may want to include the 11-year cyclic modulation of the cosmic radiation and explore potential effects of varying the longitudinal position of the geomagnetic pole. Ensemble simulations would allow for more robust results and better statistics. Moreover, although our model does include an interactive ocean and sea ice component, 50 year simulations might be too short to see possible oceanic feedbacks. Note also that this study investigated only the effects of GCRs on atmospheric ionization and the direct dynamical 
responses to changing atmospheric chemistry and temperature. Other mechanisms have been suggested, e.g. ionizationinduced changes in nucleation and cloud formation or impacts on the atmospheric electric circuit. For an overview see Kirkby (2007).

Acknowledgements. We would like to thank Eugene Rozanov and Andrea Stenke for helpful comments at various stages of this research. Special thanks go to Markus Thürkow from FU Berlin for he kindly provided the initial land surface data set and ocean temperatures and we also express our greatest thanks for the ionization look-up table from Ilya Usoskin, originally developed for the work of Marco Calisto. J. Anet is supported by the Swiss National Science Foundation (SNF) under the grant CRSI122130642(FUPSOL) and R. Zech acknowledges the support through SNF Ambizione PZ00P2_131670.

Edited by: E. Wolff

\section{References}

Anet, J. G., Muthers, S., Rozanov, E., Raible, C. C., Peter, T., Stenke, A., Shapiro, A. I., Beer, J., Steinhilber, F., Brönnimann, S., Arfeuille, F., Brugnara, Y., and Schmutz, W.: Forcing of stratospheric chemistry and dynamics during the Dalton Minimum, Atmos. Chem. Phys., 13, 10951-10967, doi:10.5194/acp13-10951-2013, 2013.

Bazilevskaya, G. A. and Svirzhevskaya, A. K.: On the stratospheric measurements of cosmic rays, Space Sci. Rev., 85, 431-521, doi:10.1023/a:1005029832052, 1998.

Bazilevskaya, G. A., Usoskin, I. G., Flueckiger, E. O., Harrison, R. G., Desorgher, L., Buetikofer, R., Krainev, M. B., Makhmutov, V. S., Stozhkov, Y. I., Svirzhevskaya, A. K., Svirzhevsky, N. S., and Kovaltsov, G. A.: Cosmic ray induced ion production in the atmosphere, Space Sci. Rev., 137, 149-173, doi:10.1007/s11214-008-9339-y, 2008.

Braconnot, P., Otto-Bliesner, B., Harrison, S., Joussaume, S., Peterchmitt, J.-Y., Abe-Ouchi, A., Crucifix, M., Driesschaert, E., Fichefet, Th., Hewitt, C. D., Kageyama, M., Kitoh, A., Laîné, A., Loutre, M.-F., Marti, O., Merkel, U., Ramstein, G., Valdes, P., Weber, S. L., Yu, Y., and Zhao, Y.: Results of PMIP2 coupled simulations of the Mid-Holocene and Last Glacial Maximum Part 1: experiments and large-scale features, Clim. Past, 3, 261277, doi:10.5194/cp-3-261-2007, 2007.

Caballero-Lopez, R. A. and Moraal, H.: Limitations of the force field equation to describe cosmic ray modulation, J. Geophys. Res.-Space, 109, A01101, doi:10.1029/2003JA010098, 2004.

Cai, W. and Cowan, T.: Trends in Southern Hemisphere circulation in IPCC AR4 models over 1950-99: ozone depletion versus greenhouse forcing, J. Climate, 20, 681-693, doi:10.1175/jcli4028.1, 2007.

Calisto, M., Usoskin, I., Rozanov, E., and Peter, T.: Influence of Galactic Cosmic Rays on atmospheric composition and dynamics, Atmos. Chem. Phys., 11, 4547-4556, doi:10.5194/acp-114547-2011, 2011.

Christl, M., Mangini, A., Holzkamper, S., and Spotl, C.: Evidence for a link between the flux of galactic cosmic rays and Earth's climate during the past $200000 \mathrm{yr}$, J. Atmos. Sol.-Terr. Phys., 66, 313-322, doi:10.1016/j.jastp.2003.12.004, 2004.

Denton, G. H., Heusser, C. J., Lowell, T. V., Moreno, P. I., Andersen, B. G., Heusser, L. E., Schluchter, C., and Marchant, D. R.: Interhemispheric linkage of paleoclimate during the last glaciation, Geogr. Ann. A, 81, 107-153, doi:10.1111/14680459.00055, 1999.

Egorova, T. A., Rozanov, E. V., Zubov, V. A., and Karol, I. L.: Model for investigating ozone trends (MEZON), Izv. Atmos. Ocean. Phys., 39, 277-293, 2003.

Egorova, T., Rozanov, E., Zubov, V., Manzini, E., Schmutz, W., and Peter, T.: Chemistry-climate model SOCOL: a validation of the present-day climatology, Atmos. Chem. Phys., 5, 1557-1576, doi:10.5194/acp-5-1557-2005, 2005.

Espizua, L. E.: Pleistocene glaciations in the Mendoza Andes, Argentina, Quaternary Glaciations-Extent and Chronology, Pt 3: South America, Asia, Africa, Australia, Antarctica, edited by: Ehlers, J. and Gibbard, P. L., Elsevier, Amsterdam, the Netherlands, 2, 69-73, 2004.

Garreaud, R. D.: Precipitation and circulation covariability in the extratropics, J. Climate, 20, 4789-4797, doi:10.1175/jcli4257.1, 2007.

Gleeson, L. J. and Axford, W. I.: Solar modulation of galactic cosmic rays, Astrophys. J., 154, 1011-1026, doi:10.1086/149822, 1968.

Hahn, A., Kliem, P., Ohlendorf, C., Zolitschka, B., Rosen, P., and Team, P. S.: Climate induced changes as registered in inorganic and organic sediment components from Laguna Potrok Aike (Argentina) during the past $51 \mathrm{ka}$, Quaternary Sci. Rev., 71, 154166, doi:10.1016/j.quascirev.2012.09.015, 2013.

Hemming, S. R.: Heinrich events: massive late pleistocene detritus layers of the North Atlantic and their global climate imprint, Rev. Geophys., 42, RG1005, doi:10.1029/2003rg000128, 2004.

Heusser, C. J.: Southern Westerlies during the Last Glacial Maximum, Quaternary Res., 31, 423-425, doi:10.1016/00335894(89)90049-5, 1989.

Hoyle, C.: Three dimensional chemical transport model study of ozone and related gases 1960-2000, Ph.D. thesis, ETHZ, Zürich, 2005.

Jansen, E., Overpeck, J., Briffa, K., Duplessy, J.-C., Joos, F., Masson-Delmotte, V., Olago, D., Otto-Bliesner, B., Peltier, W., Rahmstorf, S., Ramesh, R., Raynaud, D., Rind, D., Solomina, O., Villalba, R., and Zhang, D.: Palaeoclimate, in: Climate Change 2007: The Physical Science Basis, Contribution of Working Group I to the Fourth Assessment Report of the Intergovernmental Panel on Climate Change, Report, Cambridge University Press, Cambridge, UK and New York, NY, USA, 2007.

Kirkby, J.: Cosmic rays and climate, Surv. Geophys., 28, 333-375, doi:10.1007/s10712-008-9030-6, 2007.

Kohfeld, K. E., Graham, R. M., de Boer, A. M., Sime, L. C., Wolff, E. W., Le Quere, C., and Bopp, L.: Southern Hemisphere westerly wind changes during the Last Glacial Maximum: paleo-data synthesis, Quaternary Sci. Rev., 68, 76-95, doi:10.1016/j.quascirev.2013.01.017, 2013.

Liebowitz, A., Aydin, K. M., Verhulst, K. R., and Saltzman, E. S.: A comparison of Methyl Bromide measurements in ice core air from four Antarctic sites, AGU Fall Meeting Abstracts, Washington, D.C., USA, 2009. 
Lowell, T. V., Heusser, C. J., Andersen, B. G., Moreno, P. I., Hauser, A., Heusser, L. E., Schluchter, C., Marchant, D. R., and Denton, G. H.: Interhemispheric correlation of late pleistocene glacial events, Science, 269, 1541-1549, doi:10.1126/science.269.5230.1541, 1995.

Maldonado, A., Betancourt, J. L., Latorre, C., and Villagran, C.: Pollen analyses from a $50000 \mathrm{yr}$ rodent midden series in the southern Atacama Desert $\left(25^{\circ} 30^{\prime} \mathrm{S}\right)$, J. Quaternary Sci., 20, 493-507, doi:10.1002/jqs.936, 2005.

Manzini, E., Giorgetta, M. A., Esch, M., Kornblueh, L., and Roeckner, E.: The influence of sea surface temperatures on the northern winter stratosphere: ensemble simulations with the MAECHAM5 model, J. Climate, 19, 3863-3881, doi:10.1175/jcli3826.1, 2006.

Markgraf, V., Dodson, J. R., Kershaw, A. P., McGlone, M. S., and Nicholls, N.: Evolution of late Pleistocene and Holocene climates in the circum-South Pacific land areas, Clim. Dynam., 6, 193-211, 1992.

Marsland, S. J., Haak, H., Jungclaus, J. H., Latif, M., and Roske, F.: The Max-Planck-Institute global ocean/sea ice model with orthogonal curvilinear coordinates, Ocean Model., 5, 91-127, doi:10.1016/s1463-5003(02)00015-x, 2003.

Mix, A. C., Bard, E., and Schneider, R.: Environmental processes of the ice age: land, oceans, glaciers (EPILOG), Quaternary Sci. Rev., 20, 627-657, doi:10.1016/s0277-3791(00)00145-1, 2001.

Nowaczyk, N. R., Arz, H. W., Frank, U., Kind, J., and Plessen, B.: Dynamics of the Laschamp geomagnetic excursion from Black Sea sediments, Earth Planet. Sc. Lett., 351, 54-69, doi:10.1016/j.epsl.2012.06.050, 2012.

Polvani, L. M., Waugh, D. W., Correa, G. J. P., and Son, S.W.: Stratospheric ozone depletion: the main driver of twentiethcentury atmospheric circulation changes in the Southern Hemisphere, J. Climate, 24, 795-812, doi:10.1175/2010jcli3772.1, 2011

Porter, H. S., Jackman, C. H., and Green, A. E. S.: Efficiencies for production of atomic nitrogen and oxygen by relativistic proton impact in air, J. Chem. Phys., 65, 154-167, doi:10.1063/1.432812, 1976.

Potgieter, M. S.:Solar Modulation of Cosmic Rays, Living Rev. Sol. Phys., 10, 3, doi:10.12942/lrsp-2013-3, 2013.

Roeckner, E., Bäuml, G., Bonaventura, L., Brokopf, R., Esch, M., Giorgetta, M., Hagemann, S., Kirchner, I., Kornblueh, L., Manzini, E., Rhodin, A., Schlese, U., Schulzweida, U., and Tompkins, A.: The atmospheric general circulation model ECHAM 5, Part I: Model description, Report, Max-PlanckInstitut für Meteorologie, Hamburg, Germany, 2003.

Roeckner, E., Brokopf, R., Esch, M., Giorgetta, M., Hagemann, S., Kornblueh, L., Manzini, E., Schlese, U., and Schulzweida, U.: Sensitivity of simulated climate to horizontal and vertical resolution in the ECHAM5 atmosphere model, J. Climate, 19, 37713791, doi:10.1175/jcli3824.1, 2006.

Rozanov, E. V., Zubov, V. A., Schlesinger, M. E., Yang, F. L., and Andronova, N. G.: The UIUC three-dimensional stratospheric chemical transport model: description and evaluation of the simulated source gases and ozone, J. Geophys. Res.-Atmos., 104, 11755-11781, doi:10.1029/1999jd900138, 1999.

Rozanov, E. V., Schlesinger, M. E., and Zubov, V. A.: The University of Illinois, Urbana-Champaign three-dimensional stratosphere-troposphere general circulation model with interactive ozone photochemistry: fifteen-year control run climatology, J. Geophys. Res.-Atmos., 106, 27233-27254, doi:10.1029/2000jd000058, 2001.

Saltzman, E. S., Aydin, M., Williams, M. B., Verhulst, K. R., and Gun, B.: Methyl chloride in a deep ice core from Siple Dome, Antarctica, Geophys. Res. Lett., 36, L03822, doi:10.1029/2008gl036266, 2009.

Schilt, A., Baumgartner, M., Schwander, J., Buiron, D., Capron, E., Chappellaz, J., Loulergue, L., Schuepbach, S., Spahni, R., Fischer, H., and Stocker, T. F.: Atmospheric nitrous oxide during the last 140000 years, Earth Planet. Sc. Lett., 300, 33-43, doi:10.1016/j.eps1.2010.09.027, 2010.

Schraner, M., Rozanov, E., Schnadt Poberaj, C., Kenzelmann, P., Fischer, A. M., Zubov, V., Luo, B. P., Hoyle, C. R., Egorova, T., Fueglistaler, S., Brönnimann, S., Schmutz, W., and Peter, T.: Technical Note: Chemistry-climate model SOCOL: version 2.0 with improved transport and chemistry/microphysics schemes, Atmos. Chem. Phys., 8, 5957-5974, doi:10.5194/acp-8-59572008, 2008.

Sime, L. C., Kohfeld, K. E., Le Quere, C., Wolff, E. W., de Boer, A. M., Graham, R. M., and Bopp, L.: Southern Hemisphere westerly wind changes during the Last Glacial Maximum: model-data comparison, Quaternary Sci. Rev., 64, 104120, doi:10.1016/j.quascirev.2012.12.008, 2013.

Solomon, S., Rusch, D. W., Gerard, J. C., Reid, G. C., and Crutzen, P. J.: The effect of particle precipitation events on the neutral and ion chemistry of the middle atmosphere: II. Odd hydrogen, Planet. Space Sci., 29, 885-892, doi:10.1016/00320633(81)90078-7, 1981.

Son, S. W., Polvani, L. M., Waugh, D. W., Akiyoshi, H., Garcia, R., Kinnison, D., Pawson, S., Rozanov, E., Shepherd, T. G. and Shibata, K.: The impact of stratospheric ozone recovery on the Southern Hemisphere westerly jet, Science, 320, 1486-1489, doi:10.1126/science.1155939, 2008.

Son, S. W., Gerber, E. P., Perlwitz, J., Polvani, L. M., Gillett, N. P., Seo, K. H., Eyring, V., Shepherd, T. G., Waugh, D., Akiyoshi, H., Austin, J., Baumgaertner, A., Bekki, S., Braesicke, P., Bruehl, C., Butchart, N., Chipperfield, M. P., Cugnet, D., Dameris, M., Dhomse, S., Frith, S., Garny, H., Garcia, R., Hardiman, S. C., Joeckel, P., Lamarque, J. F., Mancini, E., Marchand, M., Michou, M., Nakamura, T., Morgenstern, O., Pitari, G., Plummer, D. A., Pyle, J., Rozanov, E., Scinocca, J. F., Shibata, K., Smale, D., Teyssedre, H., Tian, W., and Yamashita, Y.: Impact of stratospheric ozone on Southern Hemisphere circulation change: a multimodel assessment, J. Geophys. Res.-Atmos., 115 D00M07, doi:10.1029/2010jd014271, 2010.

Stenke, A., Schraner, M., Rozanov, E., Egorova, T., Luo, B., and Peter, T.: The SOCOL version 3.0 chemistry-climate model: description, evaluation, and implications from an advanced transport algorithm, Geosci. Model Dev., 6, 1407-1427, doi:10.5194/gmd-6-1407-2013, 2013.

Stuut, J. B. W. and Lamy, F.: Climate variability at the southern boundaries of the Namib (Southwestern Africa) and Atacama (northern Chile) coastal deserts during the last $120000 \mathrm{yr}$, Quaternary Res., 62, 301-309, doi:10.1016/j.yqres.2004.08.001, 2004.

Thompson, D. W. J. and Solomon, S.: Interpretation of recent Southern Hemisphere climate change, Science, 296, 895-899, doi:10.1126/science.1069270, 2002. 
Toggweiler, J. R., Russell, J. L., and Carson, S. R.: Midlatitude westerlies, atmospheric $\mathrm{CO}_{2}$, and climate change during the ice ages, Paleoceanography, 21, PA2005, doi:10.1029/2005pa001154, 2006.

Usoskin, I. G. and Kovaltsov, G. A.: Cosmic ray induced ionization in the atmosphere: full modeling and practical applications, J. Geophys. Res.-Atmos., 111, D21206, doi:10.1029/2006jd007150, 2006.

Usoskin, I. G., Alanko-Huotari, K., Kovaltsov, G. A., and Mursula, K.: Heliospheric modulation of cosmic rays: Monthly reconstruction for 1951-2004, J. Geophys. Res.-Space, 110, A12108, doi:10.1029/2005ja011250, 2005.

Usoskin, I. G., Kovaltsov, G. A., and Mironova, I. A.: Cosmic ray induced ionization model CRAC:CRII: an extension to the upper atmosphere, J. Geophys. Res.-Atmos., 115, D10302, doi:10.1029/2009jd013142, 2010.

Valcke, S.: The OASIS3 coupler: a European climate modelling community software, Geosci. Model Dev., 6, 373-388, doi:10.5194/gmd-6-373-2013, 2013.

Valero-Garces, B. L., Jenny, E., Rondanelli, M., DelgadoHuertas, A., Burns, S. J., Veit, H., and Moreno, A.: Palaeohydrology of Laguna de Tagua Tagua $\left(34^{\circ} 30^{\prime} \mathrm{S}\right)$ and moisture fluctuations in Central Chile for the last $46000 \mathrm{yr}$, J. Quaternary Sci., 20, 625-641, doi:10.1002/jqs.988, 2005.

Valet, J.-P. and Valladas, H.: The Laschamp-Mono lake geomagnetic events and the extinction of Neanderthal: a causal link or a coincidence?, Quaternary Sci. Rev., 29, 3887-3893, doi:10.1016/j.quascirev.2010.09.010, 2010.
Voelker, A. H. L.: Global distribution of centennial-scale records for Marine Isotope Stage (MIS) 3: a database, Quaternary Sci. Rev., 21, 1185-1212, doi:10.1016/s0277-3791(01)00139-1, 2002.

Wang, X., Auler, A. S., Edwards, R. L., Cheng, H., Ito, E., Wang, Y., Kong, X., and Solheid, M.: Millennial-scale precipitation changes in southern Brazil over the past 90,000 years, Geophys. Res. Lett., 34, L23701, doi:10.1029/2007gl031149, 2007.

Wang, Y. J., Cheng, H., Edwards, R. L., An, Z. S., Wu, J. Y., Shen, C. C., and Dorale, J. A.: A high-resolution absolute-dated Late Pleistocene monsoon record from Hulu Cave, China, Science, 294, 2345-2348, doi:10.1126/science.1064618, 2001.

Zech, R., Kull, Ch., Kubik, P. W., and Veit, H.: Exposure dating of Late Glacial and pre-LGM moraines in the Cordon de Doña Rosa, Northern/Central Chile $\left(\sim 31^{\circ} \mathrm{S}\right)$, Clim. Past, 3, 1-14, doi:10.5194/cp-3-1-2007, 2007.

Zech, R., May, J.-H., Kull, C., Ilgner, J., Kubik, P. W., and Veit, H.: Timing of the late Quaternary glaciation in the Andes from similar to 15 to $40^{\circ} \mathrm{S}$, J. Quaternary Sci., 23, 635-647, doi:10.1002/jqs.1200, 2008.

Zech, R., Zech, J., Kull, Ch., Kubik, P. W., and Veit, H.: Early last glacial maximum in the southern Central Andes reveals northward shift of the westerlies at $\sim 39 \mathrm{ka}$, Clim. Past, 7, 41-46, doi:10.5194/cp-7-41-2011, 2011. 